\title{
NUCLEAR ROCKET ENGINE DYNAMICS STUDY
}

\section{P. J. BLAKE \& W. H. ESSELMAN}

\section{MASTER}

SCIENTIFIC PAPER WANL-TNP-044

\author{
Astronuclear Laboratory \\ Westinghouse Electric Corporation
}




\section{DISCLAIMER}

This report was prepared as an account of work sponsored by an agency of the United States Government. Neither the United States Government nor any agency Thereof, nor any of their employees, makes any warranty, express or implied, or assumes any legal liability or responsibility for the accuracy, completeness, or usefulness of any information, apparatus, product, or process disclosed, or represents that its use would not infringe privately owned rights. Reference herein to any specific commercial product, process, or service by trade name, trademark, manufacturer, or otherwise does not necessarily constitute or imply its endorsement, recommendation, or favoring by the United States Government or any agency thereof. The views and opinions of authors expressed herein do not necessarily state or reflect those of the United States Government or any agency thereof. 


\section{DISCLAIMER}

Portions of this document may be illegible in electronic image products. Images are produced from the best available original document. 


\title{
NUCLEAR ROCKET ENGINE
}

\section{DYNAMICS STUDY *}

\author{
By
}

P. J. Blake and W. H. Esselman

This report was prepared as an account of work
sponsored by the United States Government. Neither
the United States nor the United States Energy
Research and Development Administration, nor any of
their employees, nor any of their contractors,
subcontractors, or their employees, makes any
warranty, express or implied, or assumes any legal
liability or responsibility for the accuracy, completeness
or usefulness of any information, apparatus, product or
process disclosed, or represents that its use would not
infringe privately owned rights.

* Presented at the International Symposium on Aero-Space Nuclear Propulsion October 23 - October 27, 1961, Las Vegas, Nevada. 


\title{
NUCLEAR ROCKET ENGINE DYNAMICS STUDY
}

\author{
P. J. Blake and W. H. Esselman \\ Westinghouse Astronuclear Laboratory \\ Pittsburgh, Pennsylvania
}

\section{Summary}

Start-up studies are reported considering first just the temperature coefficient of reactivity associated with the fuel temperature, and second, just the density coefficient of reactivity associated with the hydrogen density in a control region.

Preliminary results are given of a non-simultaneous digital-analog study of start-up which utilizes a detailed digital code description of heat transfer and fluid dynamics, and an analog description of reactor kinetics and controls.

Thrust maneuvering capabilities are explored and used as a basis for comparing control designs. Both fast and slow controllers capable of maintaining propellant exit temperature with $\pm 50^{\circ} R$ are discussed.

\section{Introduction}

For preliminary study, the dynamic response of a nuclear rocket engine can be considered in two disrinct phases; the reactor start-up, including the in itiation of propellant flow and warm-up of the engine, and the power range operation. The dynamic characteristics of a nuclear rocket engine in these two phases can be determined from analytical models, and used to establish methods for controlling the engine. Shutdown dynamics of the engine are not considered here, since they generally do not involve control stability problems and are subject to different methods of analysis.

\section{Start-Up Dynamic Response}

Start-up of a nuclear rocket engine involves the almost simultaneous increases of neutron power, propellant flow, and reactor temperature. It is necessary to determine reasonable schedules or programs of these three variables which are consistent with reactor and engine integrity and simultaneously meet the dynamics requirements. The approach used for this study was to establish the engine dynamics by a series of analog computer studies and to determine reactor and engine integrity by the development and use of digital codes.

There are two major reactivity coefficients associated with the reactors under consideration: the negative temperature ccefficient of reactivity associated with the fuel temperature, and the positive density coefficient of reactivity associated with the hydrogen propellant. These two effects occur simultaneously when external reactivity is used to raise reactor power into the power range while increasing the propellant flow through the core. An accurate representation of such a start-up was obtained in a joint digital-analog approach.

The influences of the two major reactivity coefficients affecting the engine dynamics were first studied individually to obtain a general indication of engine response.

Temperature Coefficient Controlled Start-Up

A particular feature of a nuclear rocket engine core is that it is designed for a large and rapid temperature increase during start-up. This may be of the order of $5,000 R^{\circ}$ with the change occurring at several hundred degrees per second. This can result in a sizable negative reactivity insertion and insertion rate, depending on the magnitude of the negative temperature coefficient of reactivity. The effects of this reactivity insertion are most pronounced in a start-up with zero coolant flow.

In such a stait-up, external reactivity is inserted to first bring the reactor critical and then to raise neutron level to the power range. Figures $I A$ and $I B$ show the power and the average fuel temperature during a start-up transient in which the insertion of external reactivity was continuous from source. The power peaks are not extreme, with the quasi-steady-state power reached being given by:

$$
N_{q s s}=\frac{C \times K}{a_{T}}
$$

$$
\text { Where } \begin{array}{rlr}
N & =\text { 2uasi-steady-stale power, } & \mathrm{btu} / \mathrm{sec} \\
C^{\text {qss }} & =\text { Core heat capacity, } & \mathrm{btu} / \mathrm{R}^{\circ} \\
K & =\text { External reactivity rate, } & \delta \mathrm{k} / \mathrm{sec} \\
a_{T} & =\text { Temp. coefficient of reactivity, } \delta \mathrm{k} / \mathrm{R}^{\circ}
\end{array}
$$

The rate of temperature rise is given by:

$$
\Delta T^{\prime} \sec -K^{\prime} a_{T}
$$

where $T=$ Average temperature of core in degrees 
Rankine.

By adjusting the external reactivity rate, one can thus obtain the desired rate of temperature rise. The source level will effect the initial power peak, but over a wide range of conditions little regard need be paid to detecting when the reactor achieves criticality, and in controlling the reactor period. The programming of external reactivity need not be precise and feedback from power measuring devices may possibly be eliminated during start-up.

Another form of start-up is shown in Figure 2. Here the external reactivity was limited to a value such that neutron level rose on a stable 0.6 second period into the power range. Operationally this is more difficult to accomplish than a continuous reactivity insertion since it requires more precise prediction of core reactivity conditions or measurement of the reactor period. Plots are shown for two different temperature coefficients.

The power transient is deceptively mild in appearance. For the case at the top of Figure 2, the temperature rise is as fast as $1,000 \mathrm{R} / \mathrm{sec}$ and rises $2,400 R^{\circ}$ in the first eight seconds. These values are inversely proportional to the temperature coefficient and the case at the bottom of Figure 2 shows a milder transient.

The temperature coefficient is not subject to change by the control designer, thus restricting the application of such a start-up. One variable subject to control, however, is the maximum reactivity inserted, or equivalently, the period at which the power range is approached. The time required for start-up will, however, be quite sensitive to just how precise the reactor period is controlled. The operational advantages of such a start-up must be balanced against the disadvantages of the complexity of control required.

These results and the simple equations presented are not new, but their most frequent application in the past has been in accident analyses. They are shown here in an effort to redirect thinking with regard to rocket engines--to help realize maximum advantage from the unique characteristics of nuclear rocket engines.

The problems of introducing the propellant into a hot or heating core have not been included in the above discussión. Results from calculations do, however, give encouragement in the problem of control of the engine during this phase and give an indication of inherent self-regulation of the engine.

\section{Hydrogen Density Controlled Start-Up}

Consider there to be some control region, such as a reflector, into which hydrogen is allowed to flow from a storage tank of liquid hydrogen. The hydrogen density will build up foward some maximum value dependent upon the relative flow areas into and out of the region. Suppose the reactor to be subcritical by some amount and the hydrogen to have a sufficient reactivity worth to bring the reactor critical and supercritical before the maximum hydrogen density is reached. Neutron level will rise rapidly and as it approaches the power range, the direct nuclear radiation heating of the hydrogen in the control segion will become significant, thus tending to reduce the hydrogen density. This in turn will reduce power--thus a negative power coefficient of reactivity has been postulated. It is significant that this form of reactivity feedback is very fast. There ore no time delays associated with heat transfer.

Figure 3 is typical of the results obtained for such a postulated case. Here the power transient is deceptively non-severe in appearance. It peaks at only $12 \%$ power, and the core temperature has remained essentially unchanged. Such a result is strongly dependent upon the assumed parameters and Figure 4 shows the effect of the radiation heating rate calculated for the control region. Figure 5 shows the effects of choosing different sets of flow areas resulting in different maximum flow rates. As expected, control regions with higher flow rates show a reduced sensitivity to radiation heating, resulting in higher power peaks. The flow areas are generally determined by heat transfer considerations in the steady-state but the control designer can influence the design, at least for start-up.

The results show this form of start-up to be vastly different from the temperature controlled start-up and yet to also be a reasonable form of start-up. It requires a particularly close relationship with reactor design and has a considerable influence upon power range operation. At present the major usefulness of this portion of the study has been to demonstrate the effec tiveness of the negative power coefficient of reactivity associated with the hydrogen and thus to indicate the desirable characteristics of the hydrogen propellant in the core proper.

Combined Power, Temperature, and Flow Start-Up

The most likely form of start-up to be used on an actual engine is one in which the neutron level is raised to the power range and then power and flow are programmed to give a particular temperature transient. Detailed analysis of such a start-up with liquid hydrogen appears to be a prerequisite to a full understanding of such an engine's dynamic behavior and this has been a major abjective of our analysis program. Rather than develop a complete analog model, the approach used takes advantage of some of the digital codes developed to describe reactor transient response. The development of these cades is described in a paper by F. D. Retallick 
and $B$. L. Pierce given in session $V-A$ of this meeting.

By considering in a very detailed manner the core temperatures and hydrogen conditions for assumed powers and flows, the digital code is used to determine a range of power and flow programs which are consistent with reactor flow stability, and reactor integrity. The extension to determining which power and flow programs are consistent with engine dynamics and control requires additional detailed descriptions of the engine and of the various control systems. One such extension can be shown here.

Figure 6 shows one particular power and flow program, with the resultant fuel temperature and propellant density as calculated using the digital code. These are average values obtained from the axial distributions actually calculated. These temperature and hydrogen density transients were used as inputs to an analog computer where various reactivity coefficients were associated with them. The analog computer was used to solve the reactor kinetics equations and to determine what external reactivity would be required to maintain the assumed power program. The results show that the required variations in reactivity are not rapid nor severe--and also that they are not monotonic. This last point shows the difficulty of performing a start-up using continuous reactivity insertion.

From the analog computer standpoint this was a simple study, yet the results represent a relatively highly accurate prediction of the external reactivity dynamic requirements. A high quality tool for engine dynamic analysis has thus been developed.

\section{Power Range Dynamic Response}

The objectives of this portion of the study were to:

1) Obtain a measure of the engine's dynamic capabilities.

2) Search for problem areas in engine control.

3) Determine engine stability with and without external control systems.

4) Compare alternate control systems.

An analog simulation of the engine was developed for this parametric study. The model consisted essentially of a reflector, one section core, 5-group kinetics, nozzle, turbine, pump, and control simulation.

The most useful comparative tool was that of thrust or flow demand transients. Both the rate of change and magnitude of change of flow were important, but it was found convenient to use a standard magnitude transient to keep the number of cases to be studied down to a reasonable value. A thrust change standard of $100 \%$ to $40 \%$ to $100 \%$ of rated was chosen. Figure 7 shows a typical transieni--in this case with a fast control system. The transient wos initiated by a flow demand change to the turbopump. There are both under and overshoots in temperature for each ilow change.

The control system used is shown ir. Figure 8. It uses a fast neurron level control inner loop to position mechanical contral elemenis through a fast position servo, and it has a slower temperature control outer loop which trims the power demand. Figures 9 and 10 show plots of the temperature deviations for various rates of change of flow. It is clear that the fast control system permits very rapid thrust modulation.

An alternate control system studied, which has been termed a slow control system, is shown in Figure II. Essentially it eliminates the fast neutron level inner loop and eliminates the fast position servo. The potential advantages of such a system are concerned with hardware reliability and reduced accident potential. The engine dynamic response to flow transients with slow control is very similar to that with fast control except that at faster rates of change of flow the slow control cannot follow the transient rapidly enough. Figures 9 and 10 show the temperature deviations for both the slow and fast control systems for the same transients. The slow control system is equal to the task for rates of change of flow below about $10 \%$ per second. As might be expected, it was found to be more dependent on the magnitude of the inherent reactivity effects than the fast control.

Such a comparison thus offers a basis for choosing between slow and fast control systems. If it is an engine requirement that thrust modulation be made as fast as $15 \%$ per second, then need for a fast control system is indicated. If the rate requirement is under $10 \%$ per second, then the slow control can also be used and the various reliability and safety aspects will become major factors in choosing between fast and slow control.

Another useful comparative tool was the engine response to reactivity perturbations. An interesting comparison is shown in Figure 12 which shows the power and temperature responses of an engine to reactivity steps of one dollar. The three cases shown are for the engine with no control, with slow control, and with fast control. The transient is, of course, a very severe one which neither the fast or slow control system can satisfactorily protect against. Studies have also been made with ramp reactivity insertions rather than steps, with various magnitudes of reactivity change, and for various inherent reactivity coefficients.

An example of an engine warm-up transient is shown in Figure 13. Power and flow controllers were simulated and arbitrary power and flow demands were used as input. Since the analog model was not valid near zero flow, it was necessary to simulate some low 
initial flow, but the smoothness of the power and flow obtained and the resultant temperature build-up demonstrate the controllability of such a programmed start-up.

An important variation in the warm-up program is to introduce both flow and temperature demands.

This also appears quite feasible, as shown in Figure 14. These warm-up studies on the analog computer complement the joint digital-analog start-up studies discussed previously.

The purpose of presenting these results has not been to give particular controller designs or engine responses, but rather to show how comparisons can be made between various control systems and to supply an appreciation for how fast the engine thrust can be changed. A host of other parametric study results showing the effects of various reactivity coefficients and engine parameters has not altered the basic characteristics presented here.

\section{Conclusion}

This paper has described the general features of the nuclear rocket engine dynamic analysis studies performed at the Westinghouse Astronuclear Laboratory. Analog computer studies have indicated that the nuclear rocket engine is a rather stable device and should, in principal, present no insurmountable problems for control. A wide range of control methods and systems seem feasible.

Digital computer codes have been developed to determine in great detail the dynamic characteristics of the engine for proposed power, temperature, and flow programs. These codes will be used to analyze particular start-up, accident, and other special transients, and to verify the validity of the analog model. Combined digital-analog studies will be used to obtain refined dynamic data. 
$\underline{\text { List of Figures }}$

Figure la Power Response to Continuous Reactivity Insertion

Figure $1 \mathrm{~b} \quad$ Temperature Response to Continuous Reactivity Insertion

Figure 2 Start-Up with Temperature Coefficient Control - Zero Coolant Flow and 0.6 Second Period below the Power Range

Figure 3 Start-Up with Density Coefficient Control

Figure $4 \quad$ Peak Power vs. Radiation Heating Rate

Figure 5 Peak Power vs. Reflector Steady State Flow

Figure 6 Start-Up Transient --- Digital-Analog Results

Figure $7 \quad$ Flow Transient from $100 \%$ to $40 \%$ to $100 \%$ Flow with Fast Controller. Rate of Change of Flow $=15 \%$ Per Sec.

Figure $8 \quad$ Fast Control Block Diagram

Figure 9 Temperature Overshoot and Undershoot vs, Rate of Decrease of Flow for a Total Decrease in Flow from $100 \%$ to $40 \%$.

Figure 10 Temperature Undershoot and Overshoot vs. Rate of Increase of Flow for a Total Increase in Flow from $40 \%$ to $100 \%$.

Figure $11 \quad$ Slow Control Block Diagram

Figure 12 Response to 1 Dollar Step Reactivity Insertion

Figure 13 Warm-Up with Power and Flow Programmed

Figure 14 Warm-Up with Temperature and Flow Programmed 


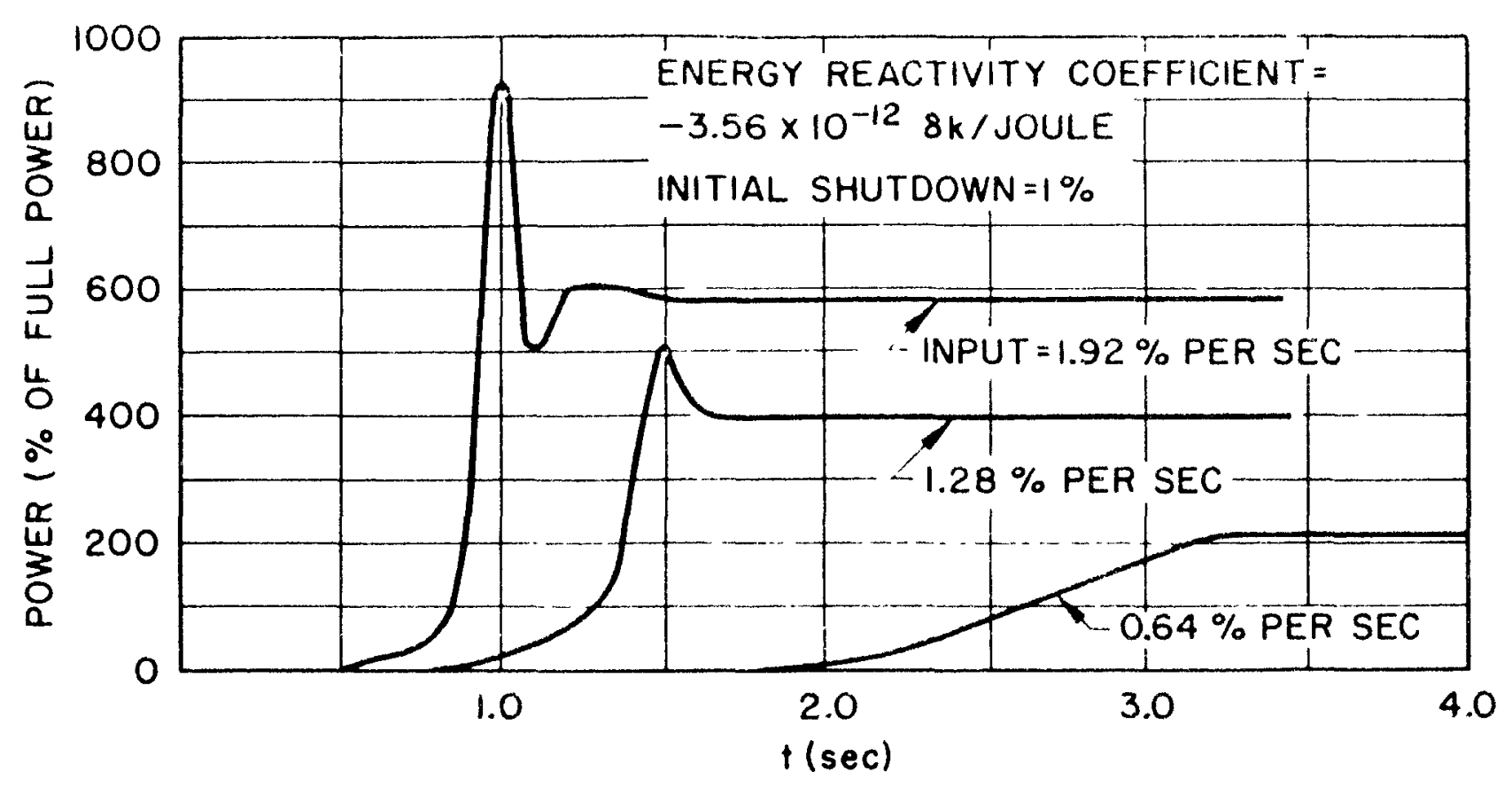

FIGURE IO-POWER RESPONSE TO CONTINUOUS REACTIVITY INSERTION

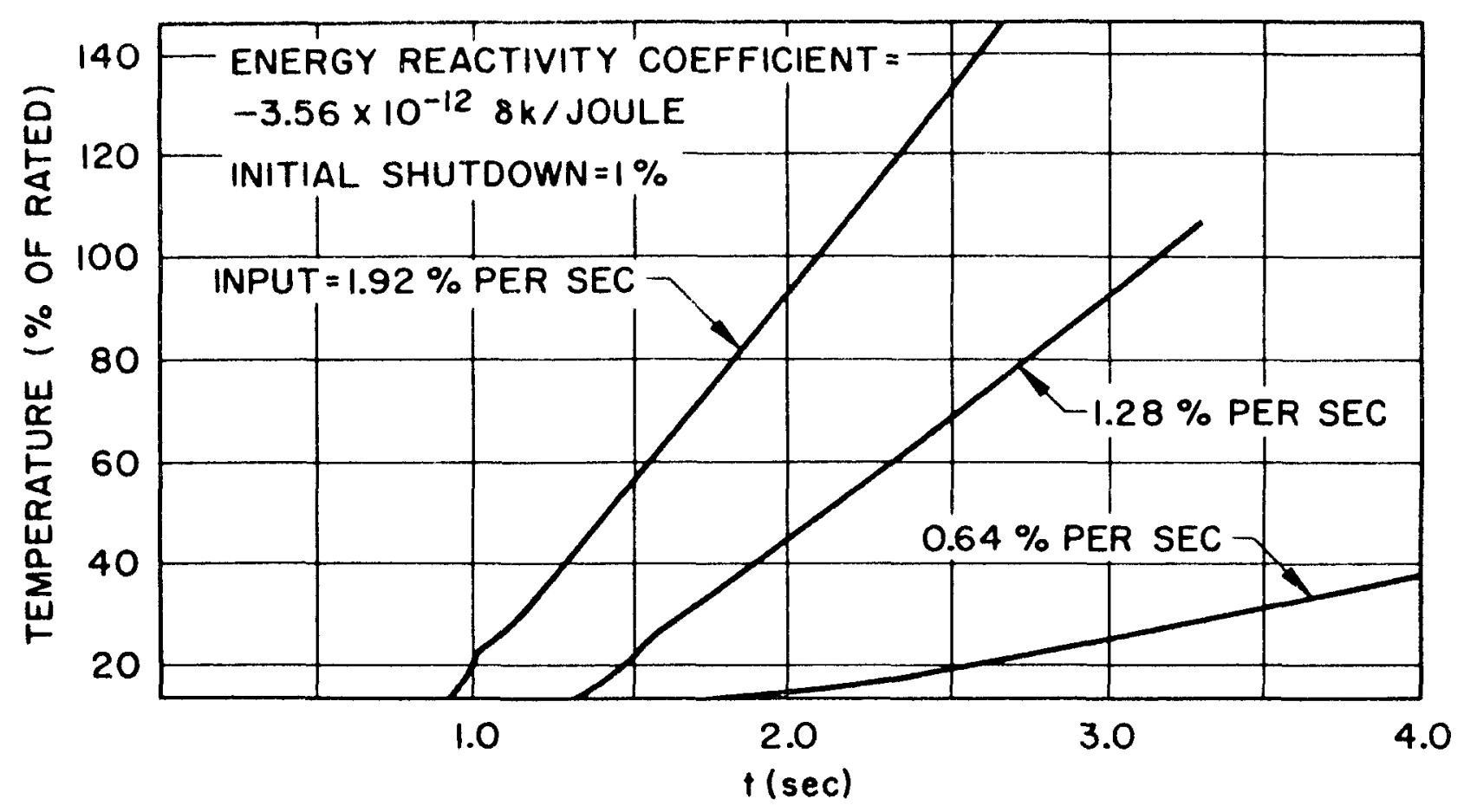

FIGURE Ib-TEMPERATURE RESPONSE TO CONTINUOUS REACTIVITY INSERTION 

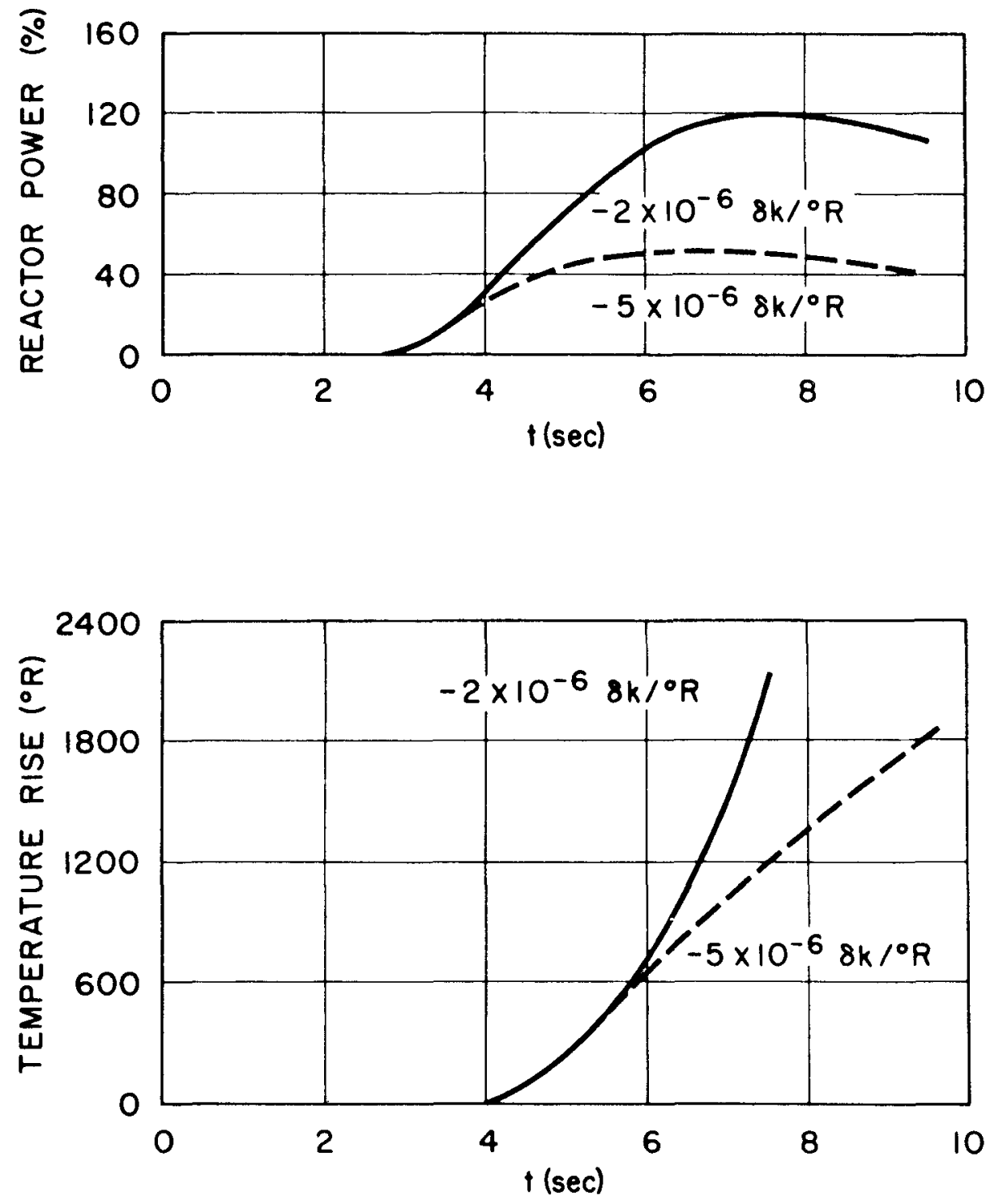

FIGURE 2 - START-UP WITH TEMPERATURE COEFFICIENT CONTROL - ZERO COOLANT FLOW AND 0.6 SECOND PERIOD BELOW THE POWER RANGE 

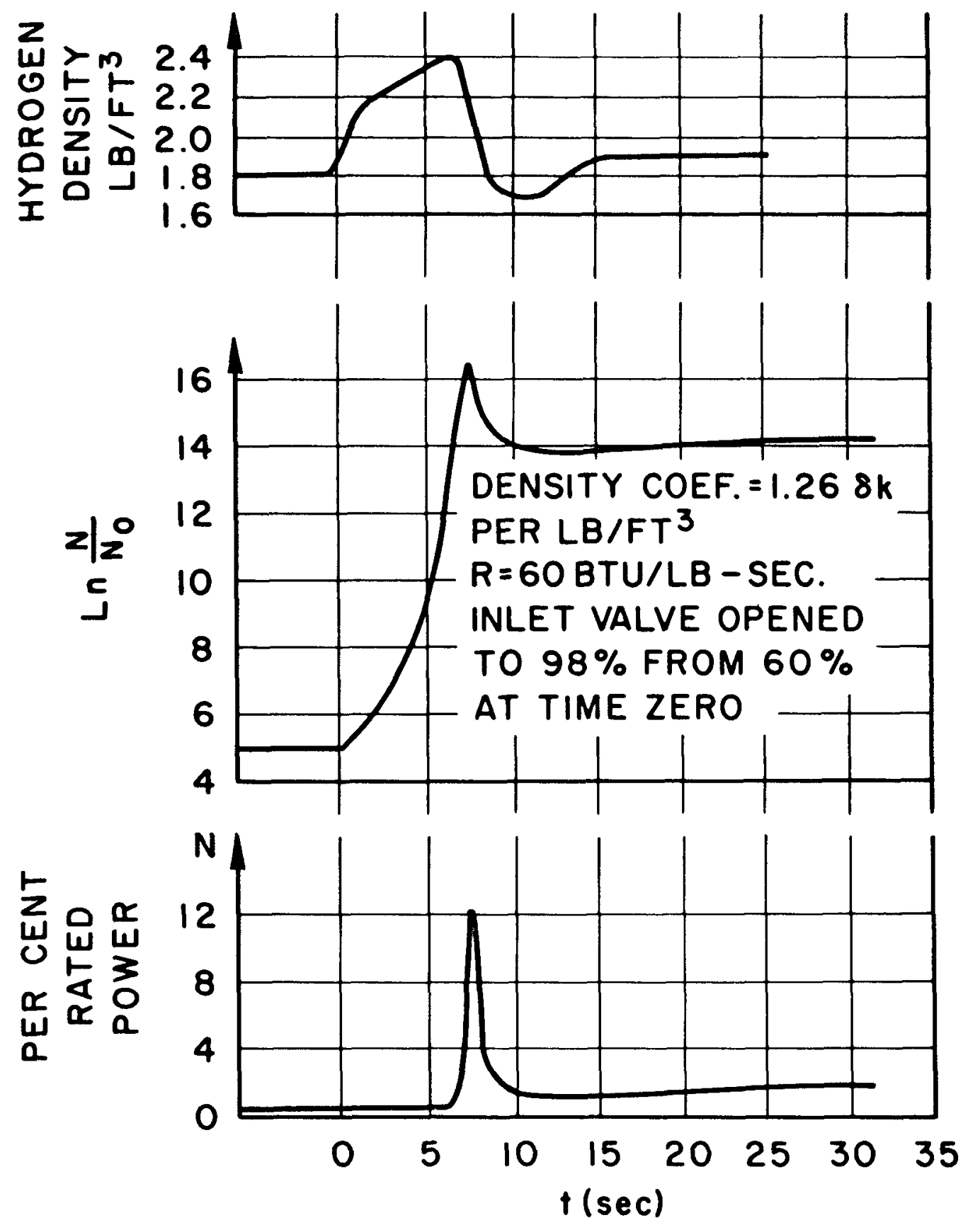

FIGURE 3-START-UP WITH DENSITY COEFFICIENT CONTROL 


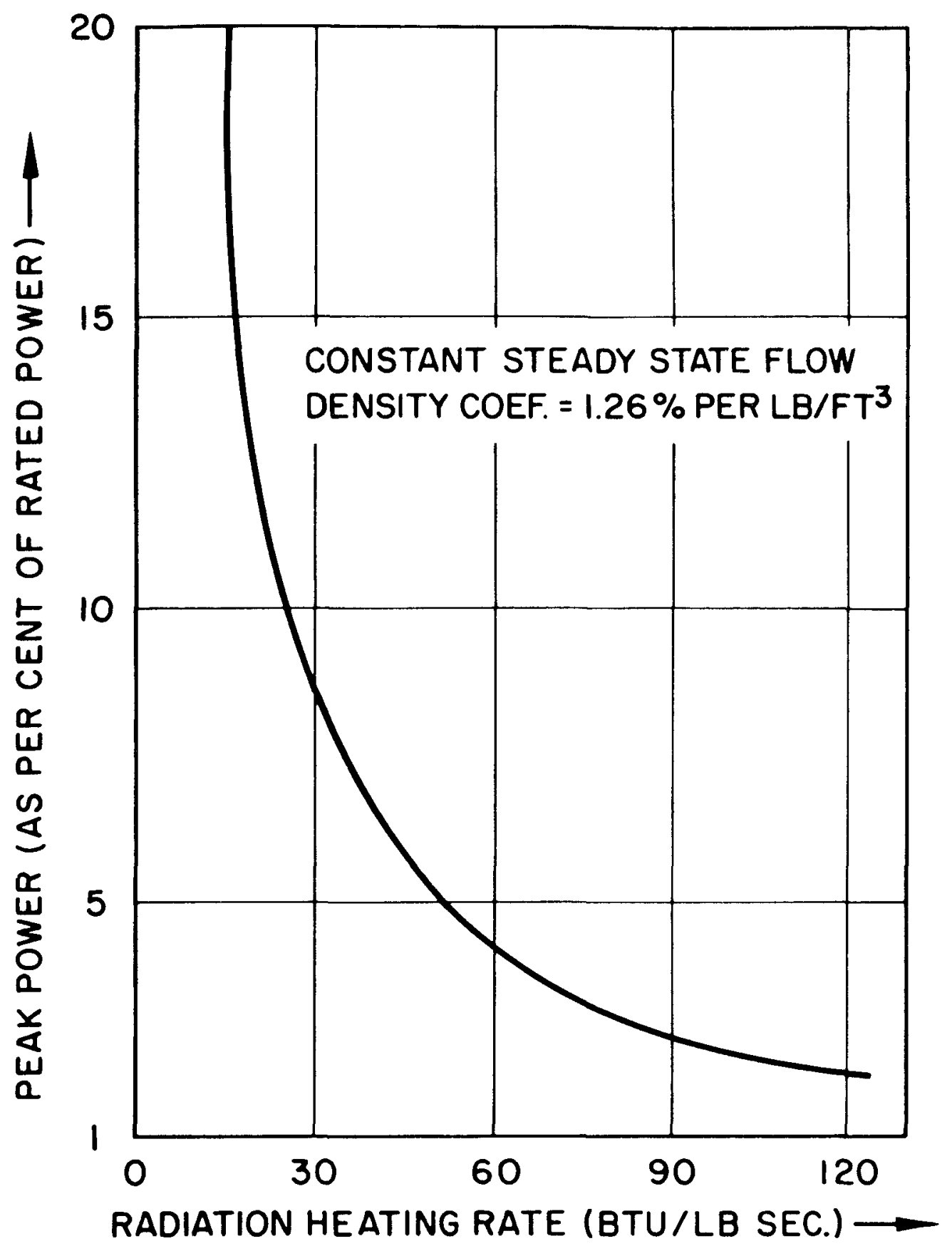

FIGURE 4 - PEAK POWER VS RADIATION HEATING RATE 


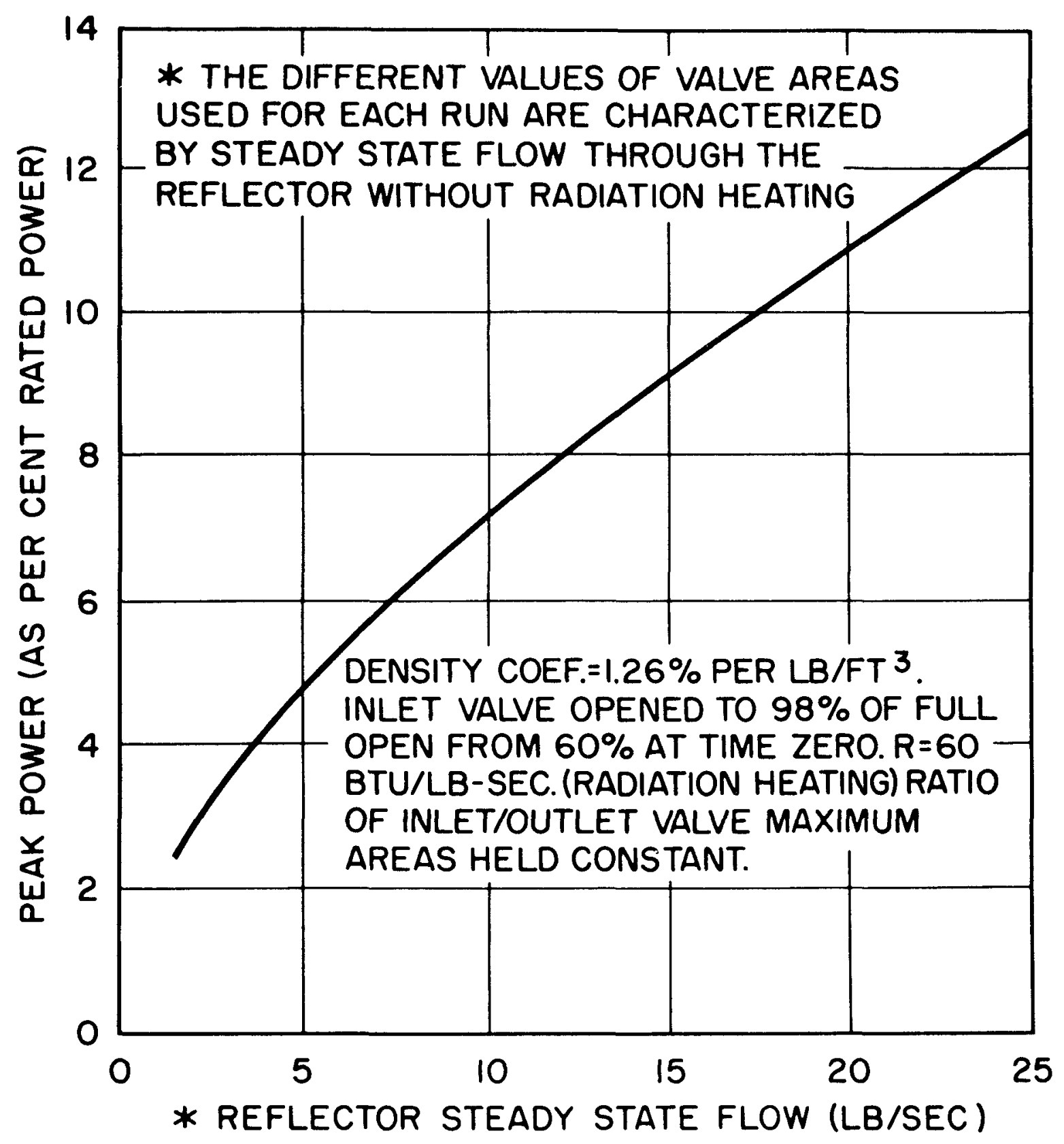

FIGURE 5-PEAK POWER VS REFLECTOR
STEADY STATE FLOW 

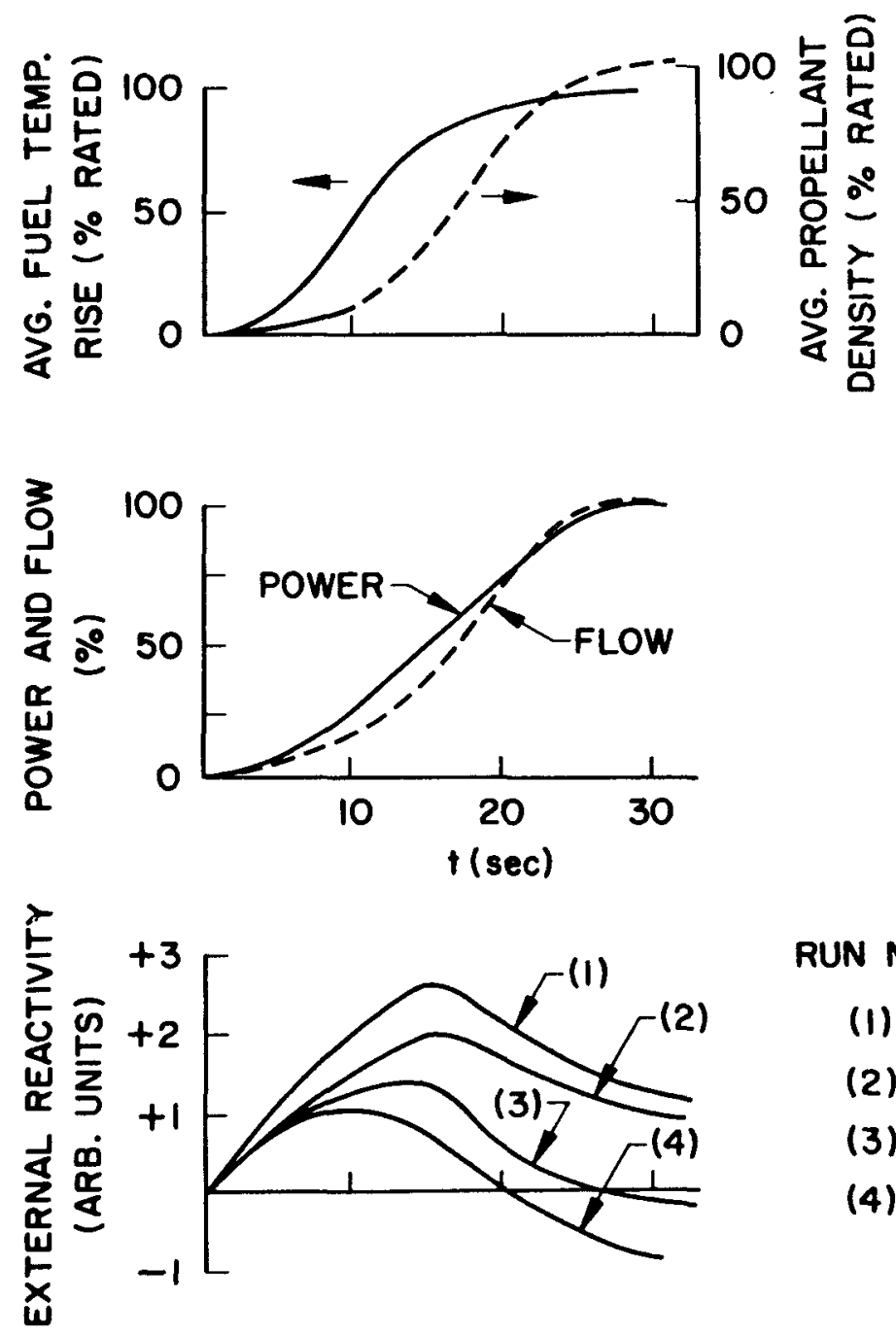

RUN NO. TEMP. COEF, $8 k / R^{\circ}$

(1) $-.6,4 \times 10^{-5}$

(2) $-.48 \times 10^{-5}$

(3) $-.32 \times 10^{-5}$

(4) $-.16 \times 10^{-5}$

FIGURE 6-START-UP TRANSIENT---DIGITAL-ANALOG RESULTS 

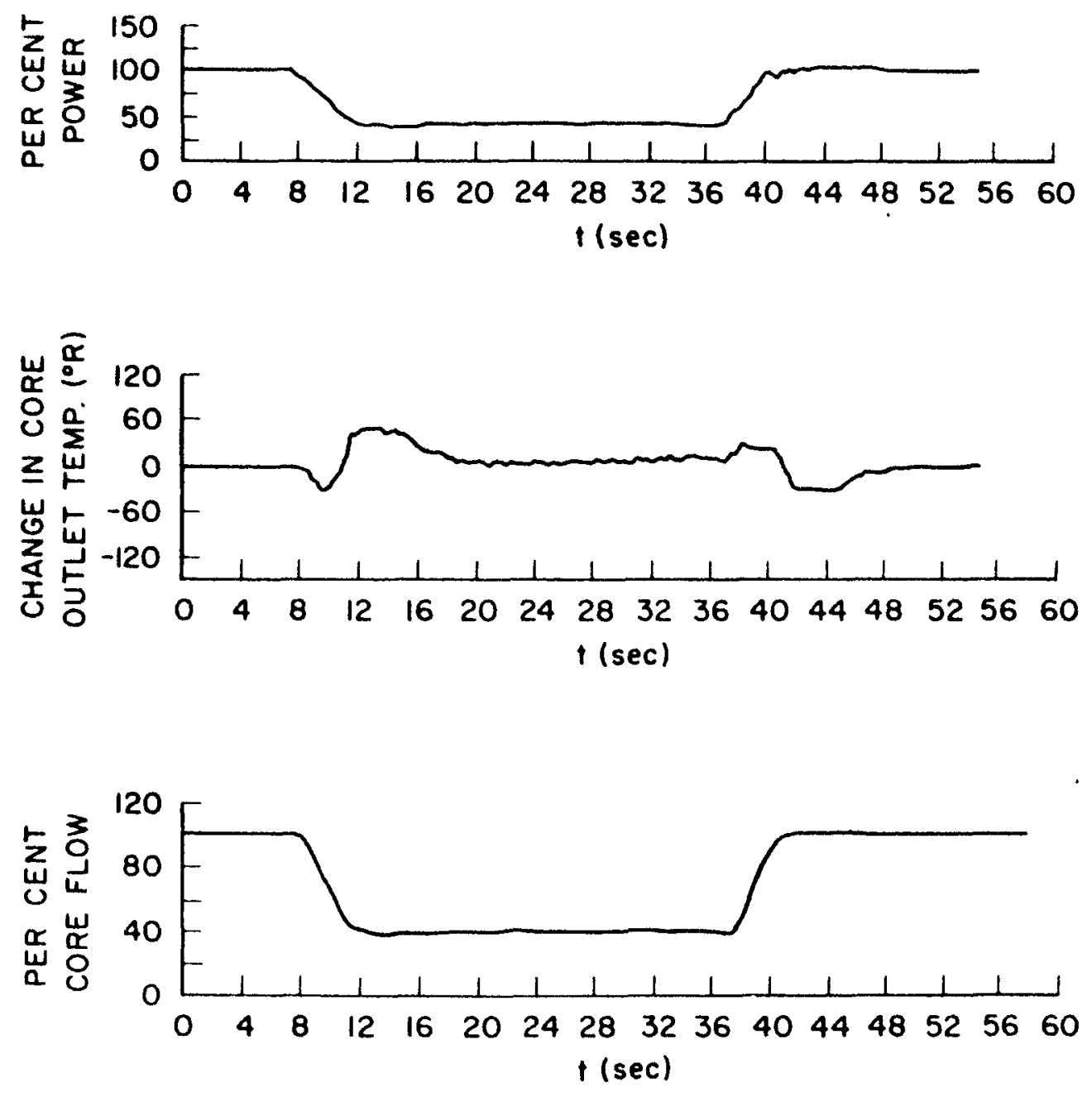

FIGURE 7 -FLOW TRANSIENT FROM 100\% TO $40 \%$ TO $100 \%$ FLOW WITH FAST CONTROLLER. RATE OF CHANGE OF FLOW $=15 \%$ PER SEC. 


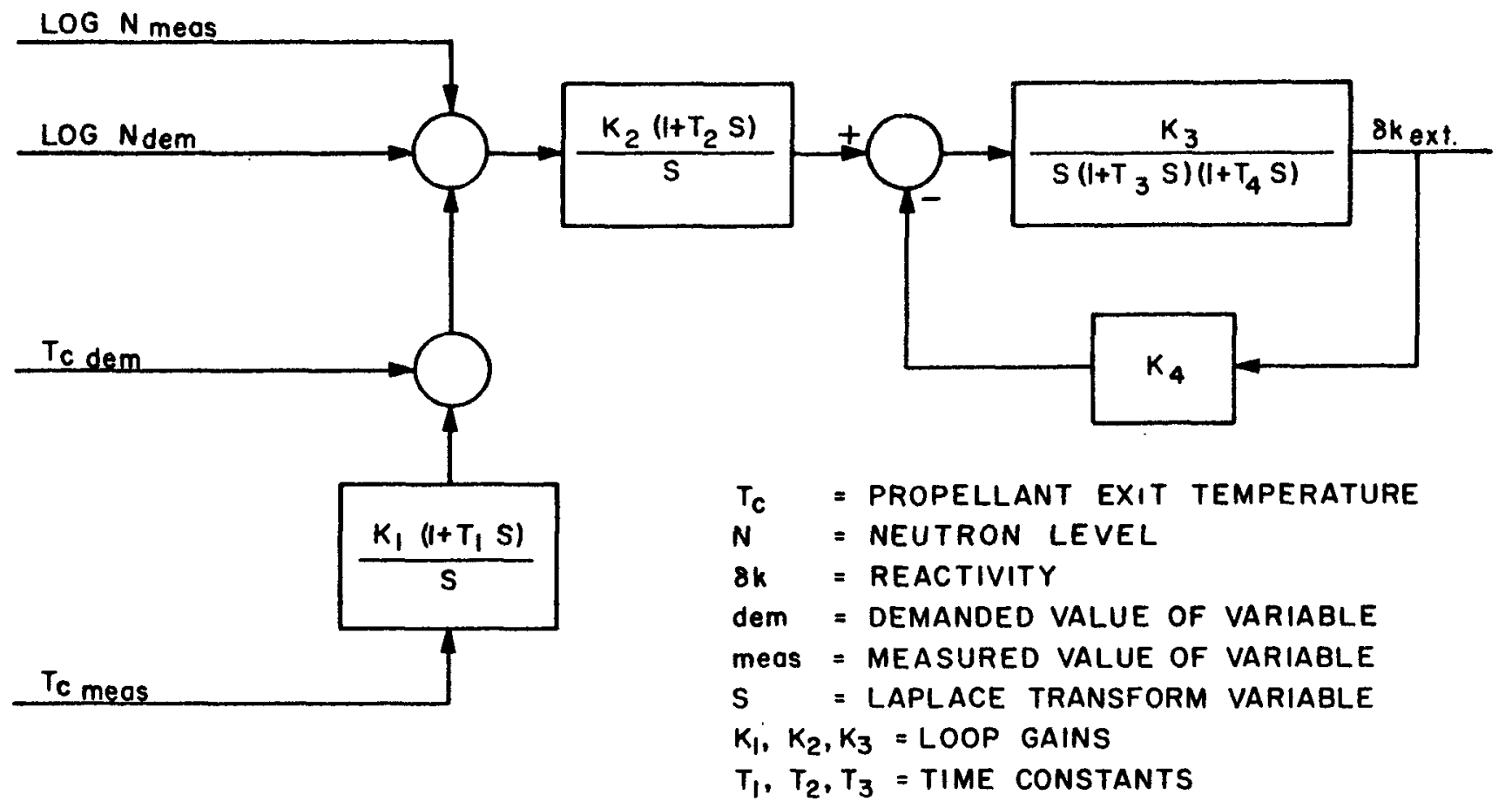

FIGURE 8 - FAST CONTROL BLOCK DIAGRAM 


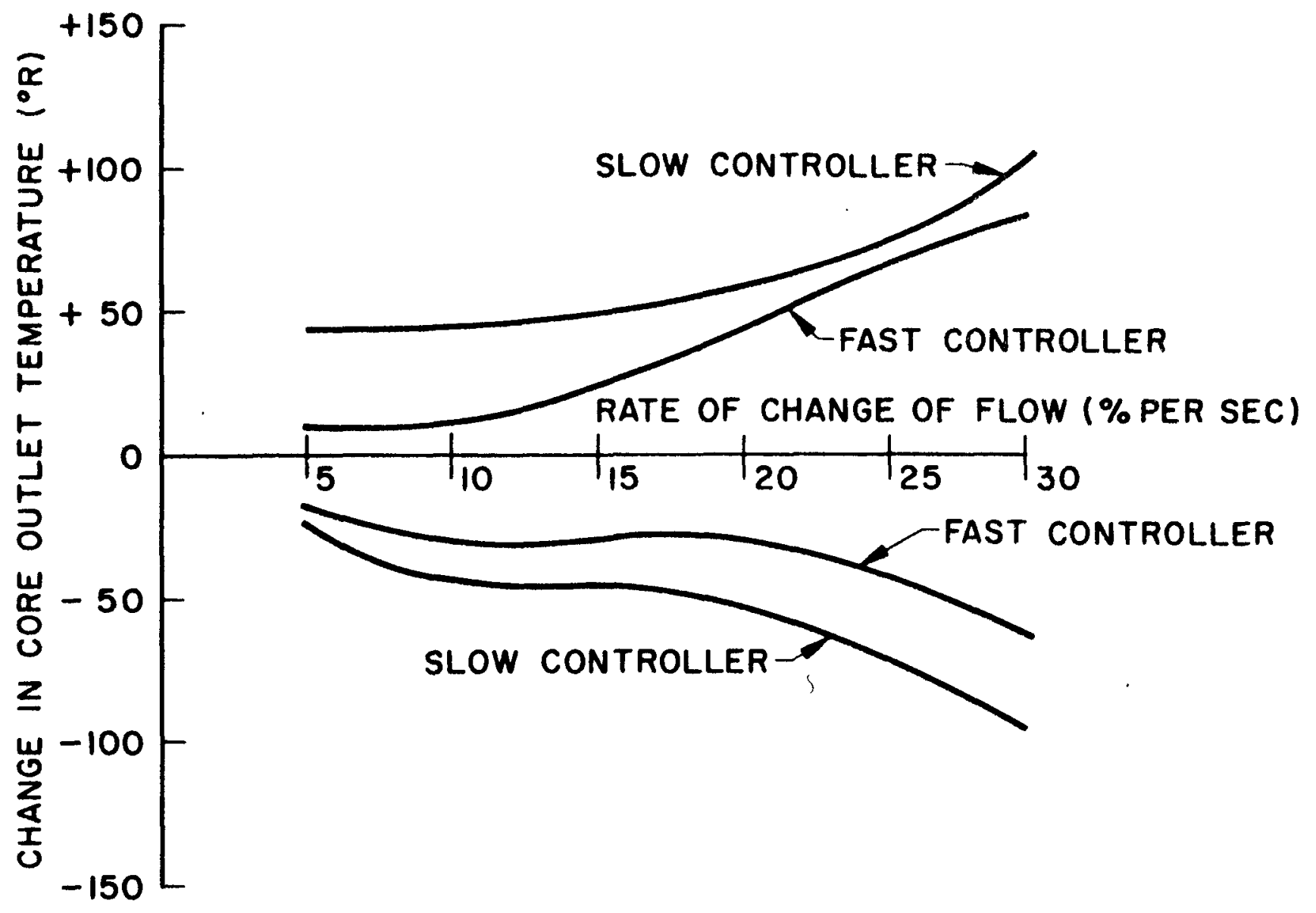

FIGURE 9-TEMPERATURE OVERSHOOT AND UNDERSHOOT VS RATE OF DECREASE OF FLOW FOR A TOTAL DECREASE IN FLOW FROM 100\% TO $40 \%$ 


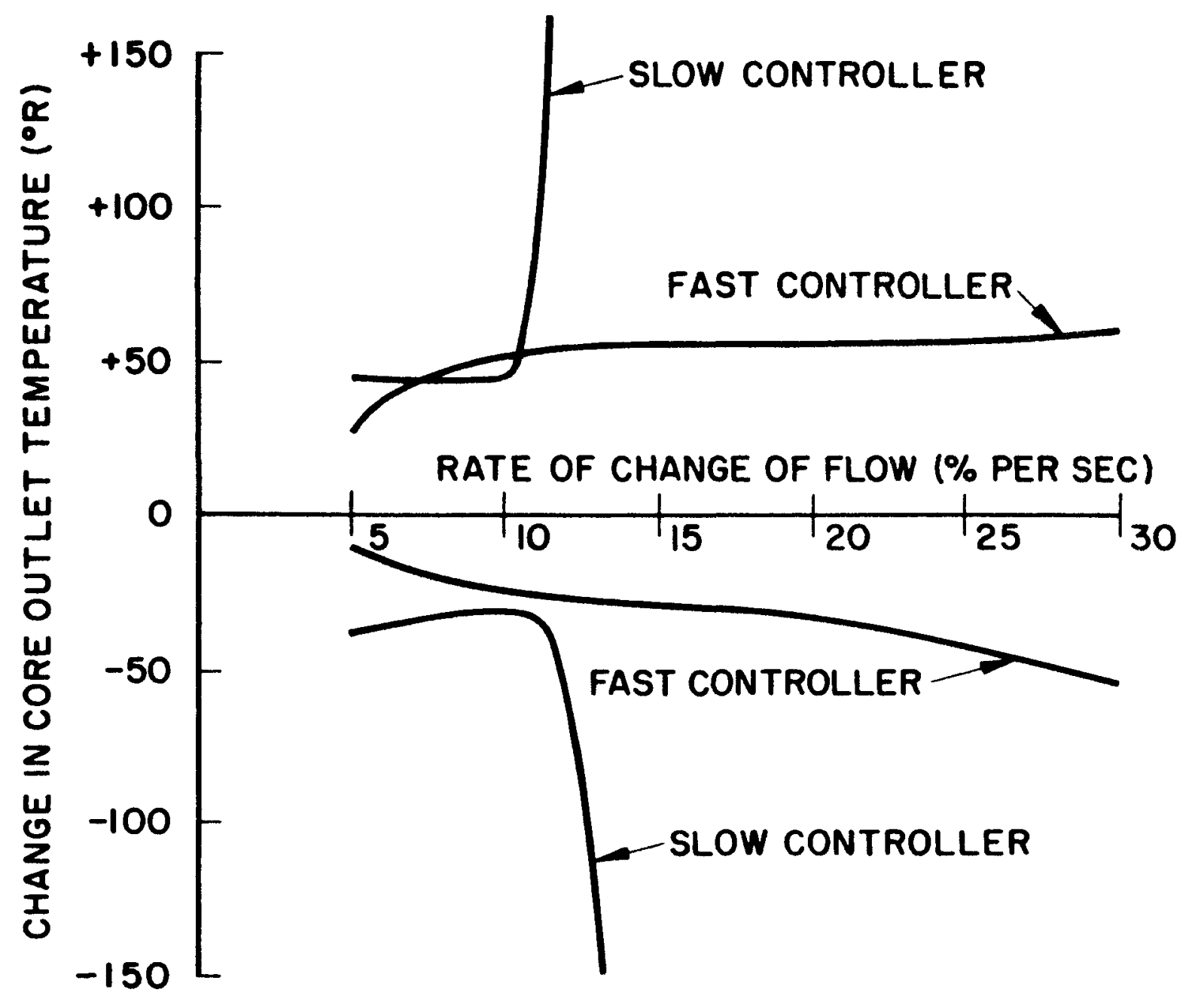

FIGURE IO-TEMPERATURE UNDERSHOOT AND OVERSHOOT vS RATE OF INCREASE OF FLOW FOR A TOTAL INCREASE IN FLOW FROM $40 \%$ TO $100 \%$ 


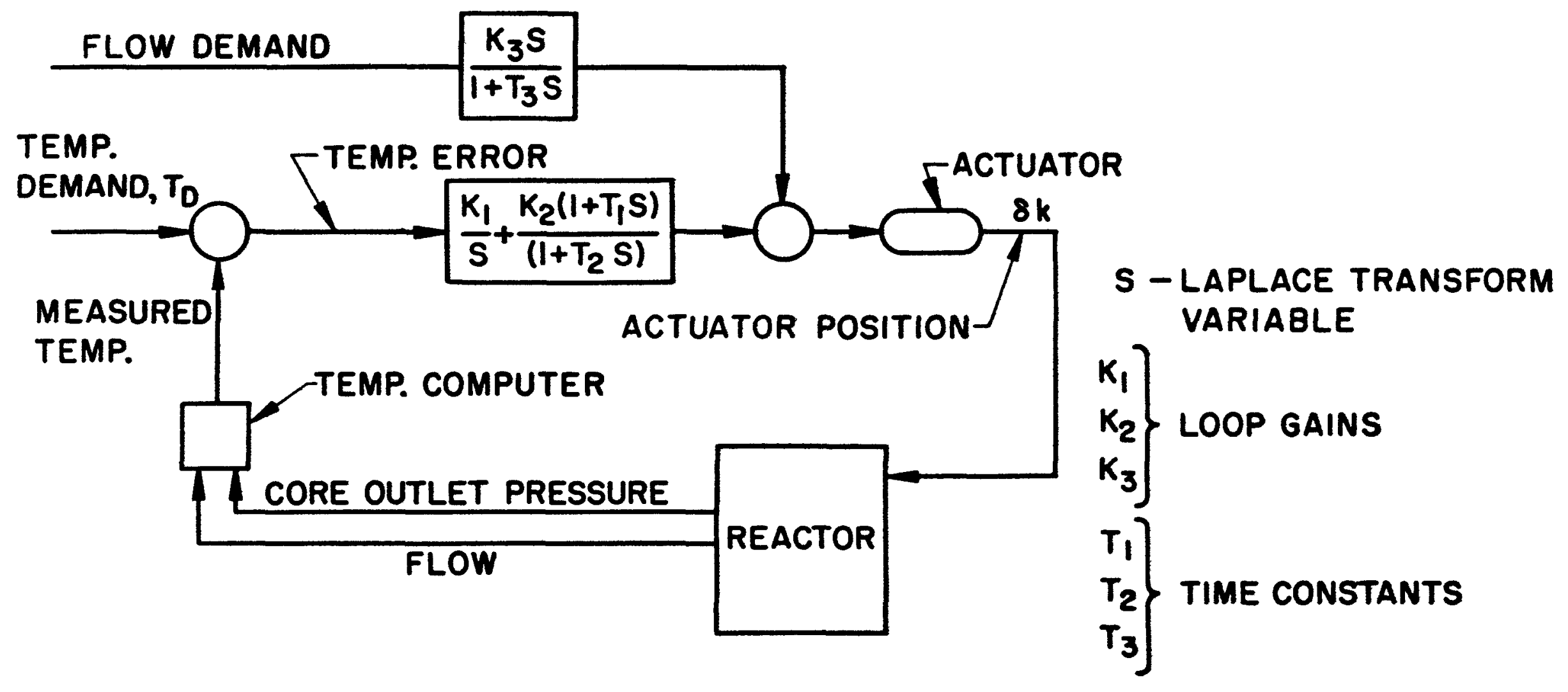

FIGURE II-SLOW CONTROL BLOCK DIAGRAM 

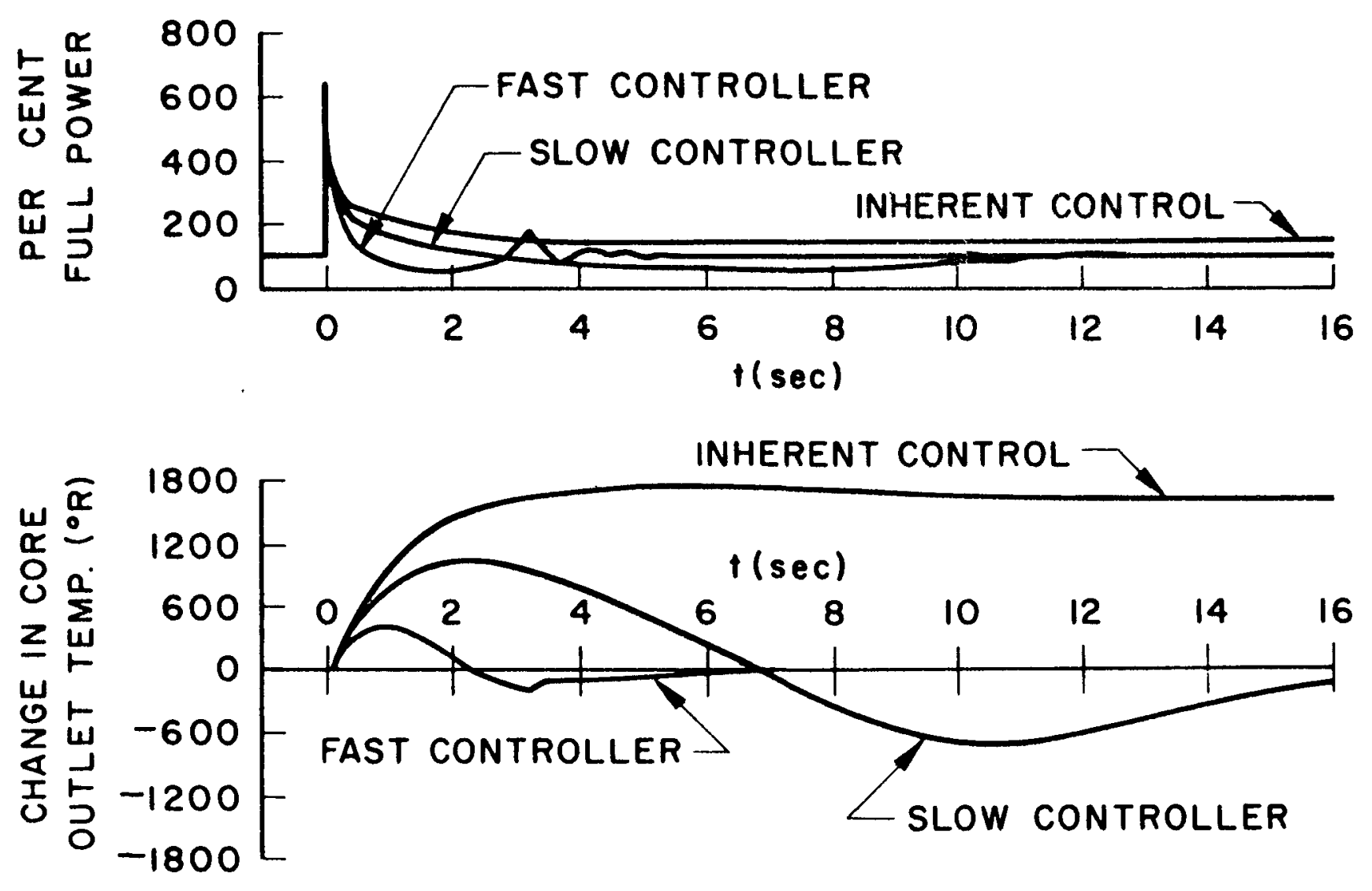

FIGURE I2-RESPONSE TO I DOLLAR STEP REACTIVITY INSERTION 

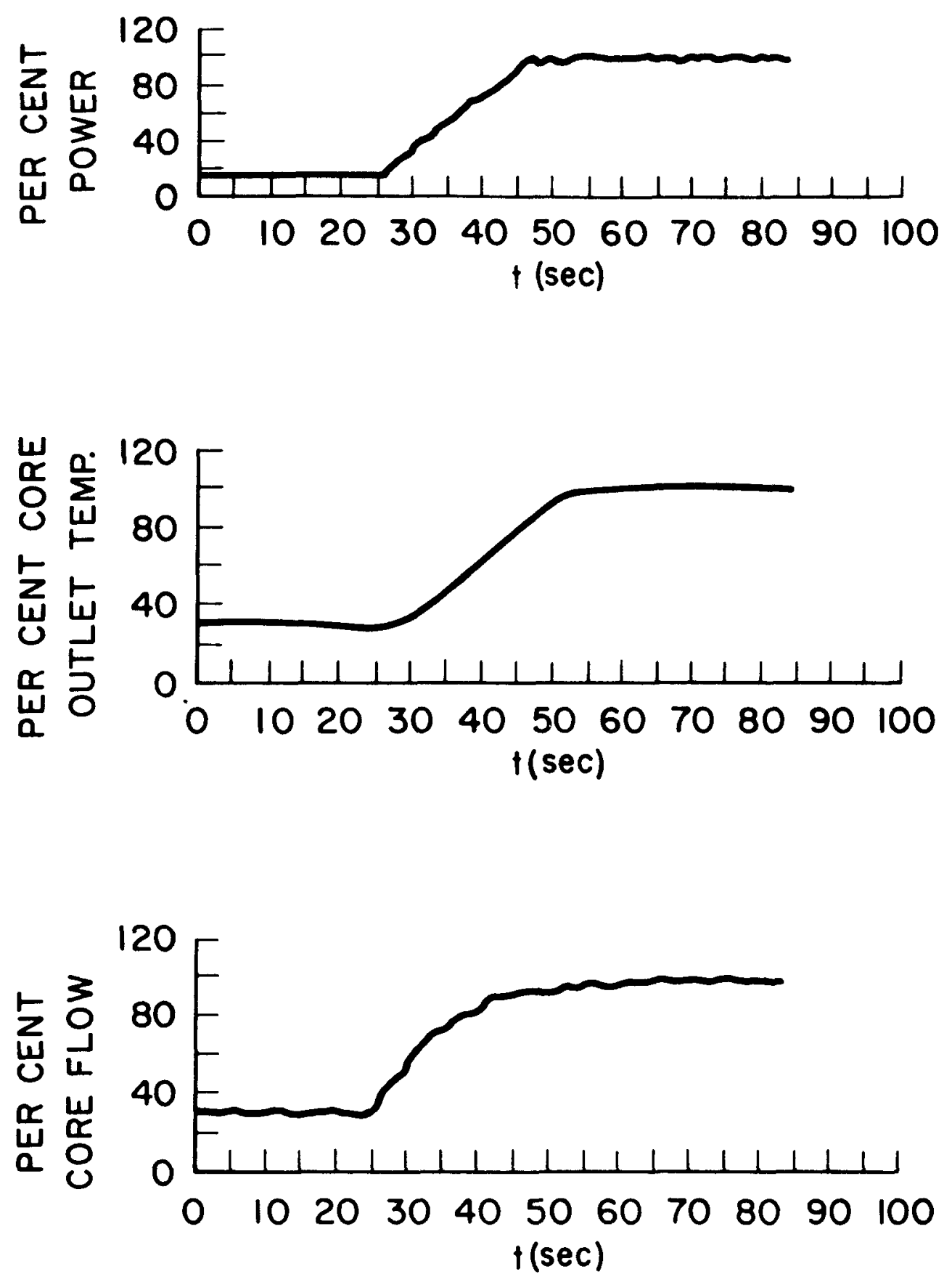

FIGURE I3-WARM-UP WITH POWER AND FLOW PROGRAMMED 

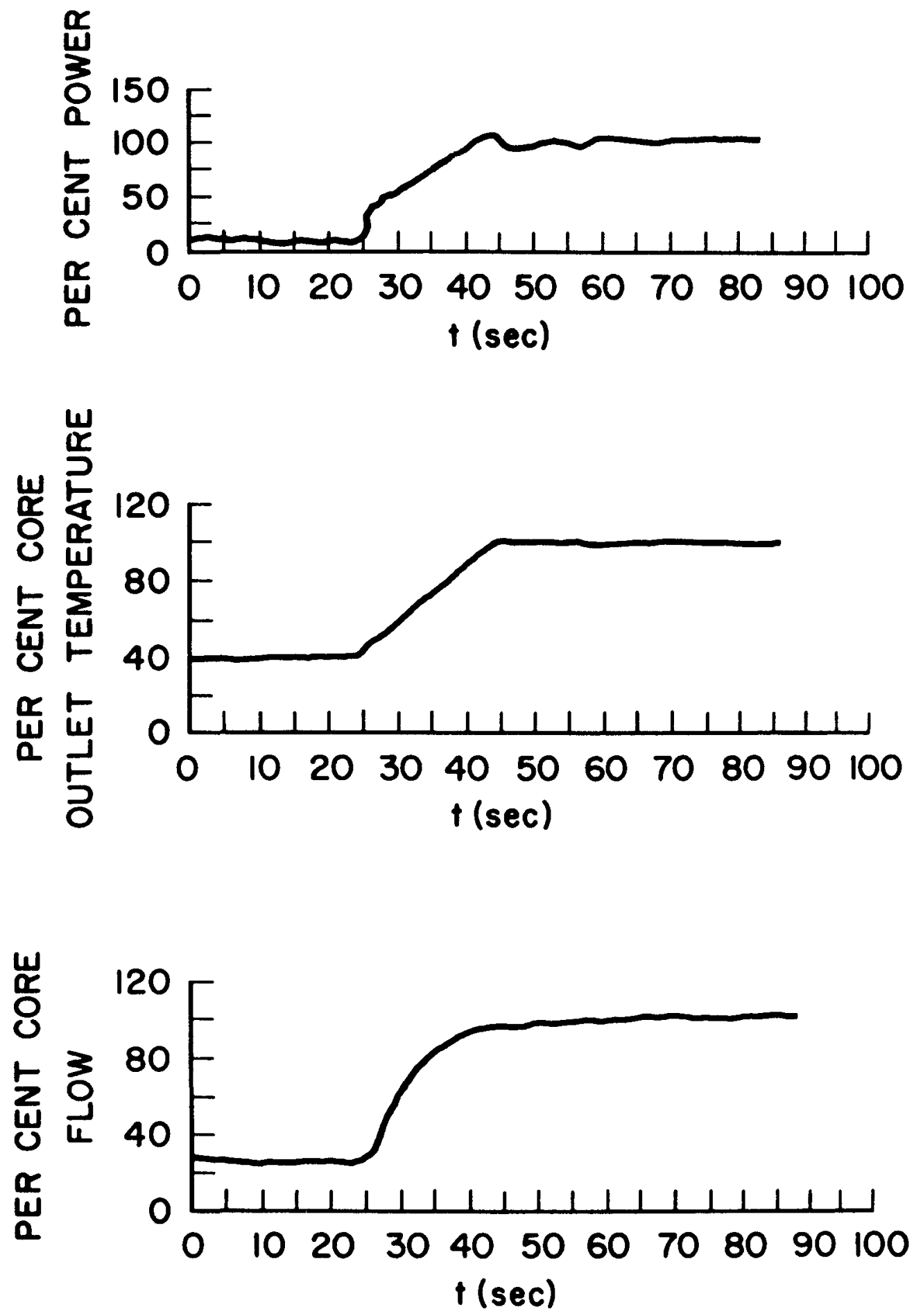

FIGURE 14-WARM-UP WITH TEMPERATURE AND FLOW PROGRAMMED 